To cite this article: Lechner, E. (2018). Migrants' lives matter: biographical research, recognition and social participation. Contemporary Social Science. DOI: $10.1080 / 21582041.2018 .1463449$

To link to this article: https://doi.org/10.1080/21582041.2018.1463449

\title{
Migrants' lives matter: biographical research, recognition and social participation
}

\author{
Elsa Lechner \\ Centre for Social Studies, University of Coimbra, Colégio de São Jerónimo, Coimbra, Portugal
}

\begin{abstract}
Since the beginning of qualitative sociology migrations have been central to the development of biographical research. Migrant communities have interested the founders of the Chicago School, also concerned by questions of isolation and prejudice among ethnic and cultural minorities. Later socio anthropological research has equally given privilege to the study of biographies of migrants, providing a paradigm shift from national understandings of migrations to transnational ones. But the analysis of the mutual effects happening between researchers and participants in such a relational kind of work asks for more attention. Drawing from empirical work conducted with migrants and refugees in Portugal, this paper proposes to deepen such analysis. Focus is brought to the subjective dimensions of the encounter happening between the different subject positions at play. It implies the incorporation of the awareness of structural inequity in the development of methodological tools capable of listening to the truth of each participant. Guided by the search for a theoretical-practical coherence, this essay proposes an analysis of the specific degrees of recognition provided by biographical research among migrants and refugees, in dialogue with the philosophical contributions of Axel Honneth and Richard Kearney. The empirical scope of this interdisciplinary proposition resonates with our public and civic research position defending that 'Migrants' Lives Matter'.
\end{abstract}

\section{Introduction}

Biographical research is a relational type of work that creates opportunities for researchers and participants to engage in an empathic endeavour, a dialogue that has the potential to change the subjectivities of their different, sometimes asymmetric, subject positions. Such potential is particularly relevant when working with underprivileged individuals or groups, such as economic migrants, and refugees who agree to participate in a research project.

Throughout the history of the social sciences (especially in sociology and anthropology), migrants and migrations have been a key topic of concern, reflection and research. Biographical research has had a foundational role studying the concrete life conditions of migrants, their life practices, representations and cultures. However, the literature on biographical research with migrants has not yet seriously focused on the transformative impacts of the special encounter that happens between a researcher and a participant. Years ago, 
general anthropological work and some qualitative sociologists have already admitted this mutual implication (namely Devereux, 1967, Geertz, 1973, Roberts, 2007), but the specificity of migration contexts requires more attention. Operational categories, social and legal statuses, determine the forms and contents of interaction between different people, and biographical research emphasises the inter-subjectivity/common humanity of those different subjects and subject positions. How might we acknowledge such ethical and psychological challenges in migration studies from a biographical research perspective?

In this paper, I take a step forward in the analysis of such implications rooted in an ethnographic standpoint influenced by the work of qualitative sociology and anthropological research on biographies and transnational migrations. In accordance with this special issue aimed at promoting interdisciplinary dialogue and stimulating reflexivity on the processes of collection, construction and interpretation of biographical accounts, I privilege the mutual learning and understanding occurring between researchers and participants in the research process, bridging biographical research with its formative and transformative effects as studied in the current of life stories in education (The Geneva School) and the 'carnal hermeneutics' of Richard Kearney (focused on conflict resolution). Drawing from empirical research developed with migrants and refugees in Portugal, I examine the formative and transformative dimensions of biographical research, identifying the question of recognition as central to its theoretical-practical coherence: acknowledging the truth of the other within biographical research methods and processes.

My suggestion is based on the concrete effects of recognition-building through biographical research where participants have been invited to produce self-narratives in groups or individually. This is interactive work that potentiates a concrete utopia of migrants' participation and empowerment through life storytelling and dialogue. The overall goal of the paper is to build upon a hypothesis of social (trans)formation in the very process of research with migrants and refugees. This practical theoretical articulation of biographical research in times of war and cultural and political crisis, builds bridges of understanding and coexistence between (different) people, in this case, between nationals and newcomers in the EU. The relevance of such a proposal seems particularly important in contexts of growing nationalisms and xenophobic movements/manifestations in our western democracies currently struggling with the challenges of cultural super-diversity and immigration.

\section{Biographical research with migrants and social participation: a practical theoretical coherence}

The title of this paper is inspired by the Black Lives Matter movement, to take a public stance before the contradictions dominating migration policies worldwide. Initiated only four years ago in the USA after the absolution of the murderer of a young AfricanAmerican - Trayvon Martin, the movement was officially recognised in 2014 against the banalisation of constant disrespect, officers and institutions included, regarding black lives. Similarly, the number of migrants' deaths in the Mediterranean Sea, or refugees in the Aegean Sea, as well as the flourishing businesses around illegal crossings, and border surveillances (Rodier, 2013), are just part of a larger picture dividing human beings into the following categories: those who are deemed worthy of living, and those who are not. In fact, the general political misconduct regarding migrants and refugees 
in the present context is just another reflex of the abyssal line (Santos, 2007), separating the world in two: the so-called developed countries and civilisations; and the uncivilised creatures of the earth. A real necropolitics (Mbembe, 2003) seems to be governing migrations internationally, and therefore, any practice respecting the lives, dignity and aspirations of migrants (forced and volunteer) represents a simple coherence with the values of justice and human rights.

In this scenario, one might understand the very work of research among such populations as an opportunity to learn about and experience super-diversity (Vertovec, 2007) from a new, decolonising perspective: bottom up versus top down, and from the inside (our own experience) versus the outside (observing the other as completely independent of ourselves). Each citizen of the world and each political community is a potential accomplice in the situation. For that reason, without any euphemism, doing research on migration is a way to reify or fight structural injustices. If we choose to practice fairness and situational equality in our fieldwork, biographical research is also and already a kind of civic intervention in and of itself (O'Neill, Roberts, \& Sparkes, 2015). The comparison between the situation of migrants and Black Americans, actually, is not new. It was already one of the premises of William Thomas - the father of American qualitative sociology with Florian Znaniecki, authors of the classic biographical work The Polish Peasant in Europe and America (1918-1925). More than one hundred years ago, two of Thomas' articles published in The American Journal of Sociology pointed to similar isolation and prejudices experienced by immigrants and blacks in American society $(1912,1914)$. The American professor established a constant parallel between the end of serfdom in Germanic and Slavic countries and the end of slavery in the USA, showing that, in both cases, liberation did not lead to the fulfilling of expectations of those looking for justice (Guth, 2004, p. 16).

Together, the focus on the biographical and the concern about social injustice regarding migrants are a heritage of the Chicago School that guide the research presented in this paper. The foundational concerns of Thomas and Znaniecki are still timely and pertinent, but the main theoretical and methodological framework inspiring the projects in analysis follows later developments promoted by French and Italian sociology, American socioanthropological studies on transnational migrants (Nina Glick-Schiller and Fouron, 2001), the practice of life storytelling in Education (Geneva School of Education) and life storytelling for conflict resolution (Richard Kearney). We might consider biographical research to be applied research drawing from concrete experience working with personal testimonials and biographical workshops with migrants. The sharing of narratives (oral, written, visual and performative) has concrete formative and transformative effects that might contribute to social change, at least at a local level, and certainly so with regard to the deconstruction of institutional discourses/official versions of 'good practices of integration' by migrant's personal testimonies.

In this line of thought, Franco Ferrarotti is a key reference since his understanding of the biographical as a nodal point ('synthetical praxis') between the collective and the singular dimensions of social life encompasses the bio-political weight of individual lives in society and in history. For Ferrarotti, biographical research is much more than sociological work with 'biographical data'. It is 'a destabilizing (civic) endeavor' (2014, p. 18) because it socialises power between participants with different statuses and functions. It shows researchers that knowledge can only be produced with field interlocutors (his or her interactors), and that knowledge production is always situated, mixed and impure, even more so among 
heterogeneous populations and cultures. The direct contact with real individuals or groups with whom the researcher works becomes then a relationship, and a complex one, where the researcher is as much questioned as the participants. The object of inquiry here is not the other, but the reciprocal interaction between the two; it is an interpersonal relation following an ideographic logic (interested in social representations), not a nomothetic one (focused in norms of behaviour and supposed trends). For Ferrarotti, as such, biographical research might revise the terms of the relationship of the human with the human, and at the same time it might revise the deep significance and social vocation of sociology as the scientific elaboration of the human condition (2014, note to the Brazilian edition of Storia et storie di vita). In practical terms, this leads to the integration of a central procedural dimension in the epistemology and methods of biographical research; to its inevitable insertion in the concrete contexts of research and to the acceptance of uncertainty in the research process.

German sociologists Gabriele Rosenthal and Artur Bogner have associated this perspective to the figurational sociology of Norbert Elias, advocating what Ferrarotti had pointed out in the 1980s in reference to the work of Sartre and his focus on History: that individuals and their memory practices are to be considered in the historical context of concrete representations and that attention must be paid to the unequal power of different people in interaction (2017). For Rosenthal and Bogner, German biographical research since the 1970 s is mostly based on the social constructivism formulated by Peter Berger and Thomas Luckmann. This involves, as in the Italian or French tradition of biographical research, the search for the subjective perspectives and experiences of social actors, understood as mutually constituted between individuals and society.

In the American context, biographical subjectivity and biography were more recently developed as a theoretical and methodological key concept in the study of migration. Nina Glick-Schiller and Georges Fouron have developed a transnational analysis of migration based on personal experiences and accounts which has introduced a paradigm shift in migration studies (2001). As Minna Ruokonen-Engler and Irina Siouti have noticed,

While classical migration research analysis traditionally concentrated on examining integration and assimilation within the paradigm of the nation state, the focus of transnationalism perspectives has underlined the intersections of the local and the global by looking at forms of interconnectedness that transcend nation-state borders. (2013, p. 248)

Further, according to Brian O'Neill, the labour of Glick-Schiller and Fouron, has accomplished the initial goal of the work with life stories in the social sciences: 'the combination of ethnographic and sociological context with the personal humanistic experience, without falling into the trap of supposed typical individuals or homogeneous cultures of origin' (2009, p. 114).

Knowing that in the Portuguese context there is an important dissonance between the official discourses on immigration ${ }^{1}$ and the concrete negative experiences reported by immigrants and associations regarding their cultural, linguistic and ethic differences, ${ }^{2}$ our research team studied the topic of immigration in Coimbra from an emic, biographical perspective. We were interested in getting to know the participant's views on their own experiences and the impacts of inter-subjectivity along a participatory research process. The goal was to hear the migrants themselves, to hear their truth, to cultivate dialogue between different people, to have access to their concrete life experiences, different 
from commonsensical discourses that reify identities and stereotypes. Following a collaborative format based on the idea of mutuality of competences (Leray \& Hamey Warou, 2014), my team and I have worked in groups which allowed migrants from many different origins to share their personal experiences and views. The biographical work groups were designed to attain that 'collective' goal and so the project ${ }^{3}$ organised 'biographical workshops' or 'story circles' where volunteer migrant participants voiced their experiences of migration to one another and to the research team. In total, we have conducted 5 biographical workshops: one with a mixed group of volunteers composed of men and women of different ages, professions, education levels, languages and religions from 12 countries (Argentina, Australia, Brazil, Cape Verde, China, Guinea Bissau, Ivory Coast, Mozambique, Russia, São Tomé, Ukraine and Uzbekistan); another group with women only (from Brazil, Mozambique, Guinea Bissau, Ukraine and Russia); a third with university students (from Argentina, Brazil, Cape Verde, China, Ivory Coast, São Tomé e Principe and Ukraine); a group with previous participants willing to talk about their different religions (Roman Catholic, Orthodox, Messianic (Johrei), Evangelical, Baptist, Mormon, Muslim, Spiritism and Candomblé); a group of foreign students living in university dorms (to talk about university housing).

Biographical workshops are working groups of volunteers who have previously learned about the project, its aims, processes, milestones in presentation meetings and public sessions like the one we organised at the community library. ${ }^{4}$ Participants agreed to voice their stories and personal accounts out loud in the group setting, where narratives were

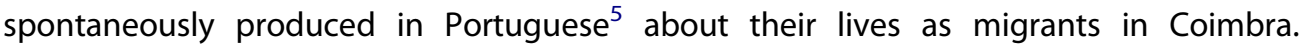
Through guided conversations and autobiographical written texts following the motto I came to Portugal', each participant told about his/her journey to Portugal, decisions to leave, itineraries and daily lives in Coimbra. At the start, participants did not know each other and did not necessarily know the team researchers. Together with our interdisciplinary team stemming from the social sciences and the humanities, migrants from many different origins living in Portugal (12 different nationalities) discussed collective topics like racism, discrimination, gender issues, work, etc. drawing from their personal experiences. Each workshop lasted three full days in which all participants spoke (in Portuguese) and listened to each other's experiences of migration with great attention. Each workshop followed a clearly established protocol for the three days (Lechner, 2012): each morning started with a listening exercise in which all participants closed their eyes for 5 minutes and were invited to listen carefully to what happened during that time. Each person then spoke of their inner experiences during the listening exercise, sharing them with the group. Such sharing enables a type of listening that is anchored in the body - respectful of differences (non-judgmental), and induces a feeling of equality, despite the diversity of shared experiences and values.

Having been trained in this kind of work, ${ }^{6}$ I have myself facilitated the group exchanges and 'orchestrated' the interactions. The fact that participants told their stories for the first time in a group of attentive listeners produced the three effects previously indicated: awareness, recognition and transformation. In very concrete ways, it allowed the deployment of new meanings to the lived experiences of narrators, the exercise of a new skill of self-presentation and the articulation in words of what was once hidden inside. Most migrants actually experience migration as a biographical disruption, a source of solitary pain and suffering. By producing audible 
narratives about those same experiences, people learn about themselves and gain awareness about the collective dimension of what they have endured. Transmuting life experiences into words functions like an exercise of self-observation and self-distancing, enabling self-reflection and knowledge with more than mere psychological relevance, that is, with self-acknowledgement and validation. As Richard Kearney affirms acknowledgement is the combination of knowledge and affect, and is the realm of narrative imagination (in Marcelo, 2017, p. 3), so narrative productions are a sine qua non condition for this transformation and, at the same time, enact the intrinsically shared humanity of knowledge and affect. Furthermore, since participants share their experiences in a group, participants learn one another, about other cultures, other ways of experiencing migration, of being in the host country and different forms of expressing those experiences. They learn respect. Moreover, this learning does not happen without relevant consequences: it has strong impacts on the participants' lives, transforming their ways of seeing and understanding migration itself. ${ }^{7}$ The formative dimension of this work, in fact, is then also already transformative given the awareness that it brings to participants who are usually socially associated with isolated groups and cultures in host societies. In this sense, biographical workshops are like labs of intercultural dialogue where different cultures, languages, religions and values have the opportunity to be in confrontation in a positive-constructive way. It is in the political weight of these stories, experiences and exchanges that we find the potential for social change of biographical research at a local level. So the 'formative art of existence' (Pineau, 1996) implicit in the work with life stories is personal and collective at the same time. The personal is political at different levels. Clearly this is a multi-scaled type of work that focuses on private accounts to address meso and macro questions relevant to life in society and in political terms. The workshops deepen the microanalysis of the produced biographical data without forgetting the larger historical and political frames. These latter factors are implicit in the narratives, conditioning the trajectory of migrants' lives, as well as the way the stories are told by concrete interlocutors. For that reason, also, the impact of narrative exchange goes beyond the self, reaching relevant aspects of life within communities and in society at large.

Based on that, both the current of life stories in education and the work of Richard Kearney for conflict resolution (www.theguestbookproject.org) apply different techniques of life storytelling, and biographical narrative production. The goal is to build social cohesion and new identities/identifications out of self-reflection, intercultural dialogue and mutual learning: a concrete practice of peace, mutual recognition and (in the case of our projects, of migrant's participation).

\section{A matter of radical recognition}

A sentence often heard during fieldwork with migrants in Coimbra, ' ... my story is not interesting', points to a self-marginalisation and self-devaluation of our interlocutors in face of institutionalised forms of power and knowledge. Yet, the accounts of those who have the concrete experience of being a migrant or a refugee are not only extremely interesting but also very relevant in political and epistemological terms. Becoming acquainted to them, and contributing to their visibility and recognition both in one-on-one relations 
and in the public sphere, entails some kind of responsibility from the researcher in the way he/she requests and respects the narratives. I understand such responsibility as an ethical, technical and civic endeavour that is materialised in a research praxis with social consequences. The theoretical and epistemological standpoint adopted here, rooted in an ecology of knowledges (Santos, 2007), becomes consistent by the application of a participatory methodology like the biographical workshops that put together researchers and migrants from many different origins.

In practical terms, this project with immigrants in Portugal reveals that recognition happens according to three main instantiations in the workshops: acknowledgement, awareness and respect. First, acknowledgement bears on the particular contexts of our interlocutors' narratives as determined by legal, social and existential statuses (they have left a concrete country, in particular conditions, being in a specific present situation, having future projects and desires). Second, participants become aware that the intentions at play during the workshops determine the interaction as these may be regulatory, dialogic, of reciprocity, civic engagement, social responsibility or participation. Finally, the respect of the Other in his/her difference and singularity appears in a reciprocal movement of understanding and dialogue where existential exchanges, learning from one another and peace-building happen. Recognition as acknowledgement, in fact, leads to recognition as awareness of such specificities. Thus engaging a process of learning mutual respect when the two parties actually meet and talk.

Proper recognition can only be achieved within an institutionalised order of rights that genuinely secures it (Williams, 1997, pp. 59-68). There are three spheres for such recognition: love within the family, contractual respect within civil society and solidarity within the state. According to this typology, rights are specifically situated in the second sphere (civil society). There one can find the 'institutions for recognition' that are supposed to guarantee the people's rights (Honneth, 2014). More specifically, Axel Honneth has shaped the concept of intersubjective recognition (1996) that is the mutual recognition occurring between subjects in a social system and forms the basis of self-confidence, self-respect and self-esteem, which are fundamental for a person's self-realisation and positive feelings towards society. When one fails to recognise the other, the affected individuals experience disrespect and offence.

Clearly, being out of place, with no sense of living in a 'common world' (Agier, 2010), as occurs for many migrants and even more refugees, reinforces exclusion and marginalisation. In the first place, being a migrant, a refugee, or an asylum seeker is already - and by definition - encapsulated in a designation that removes him or her from regular participation in society. An observation of a conversation held by a Syrian couple with the Foreign and Borders Service in Coimbra (Serviço de Estrangeiros e Fronteiras) has shown how strongly the name indicated on their residence permits (refugee or resident) counts for the definition of their situation and existential condition in the host country. By being named and considered 'immigrants', or 'refugees', their position in host countries is a different one in the face of the law. And such difference has a great impact on their own sense of belonging. Naming categories and operational concepts are a first obstacle to overcome in these encounters.

But the issue of borders is present in the interaction with migrants and refugees in other ways too. There are many different borders to take into account which represent another degree of recognition or lack of it. Namely borders that are present in the very interaction 
between national and foreign citizens, in migrants' and refugees' narratives or their life trajectories: the borders of the country left behind, those of the countries crossed (the voyage or the odyssey they went through) and those of the host country. There are yet new borders to cross in the legal access to citizenship and belonging in everyday activities or social life in the host country; linguistic and cultural borders with great impact in social relations and cultural acceptance or recognition; gendered psychological and cognitive boundaries that might be harder to overcome in particular cases (refugees are men and women, children and adults, of various social classes and levels of education, etc.). The existence of trauma, in addition, compromises even more the narratives that might be produced about such experiences. The conditions of possibility of speech (McGranahan, 2010) in those cases reveal the bio-politics of a radical recognition: one is more than his or her social and legal status. Life per se is a reason for recognition. That is a radical recognition that might support a claim for 'migrants' lives matter' in face of the disastrous way international law and the legal frame of the Nation State deals with migrants.

At another level, the particular contexts in which these narratives are produced is another step for recognition. An institutional translation (Giordano, 2008) is somehow always present in the reception of a narrative made from asymmetrical social positions and subjects. At the same time historical relations might be at play (especially between people coming from countries with a common colonial history), imposing particular identities on narrators and listeners. What can be told, what can be understood, is formatted by a structural inequality in asymmetrical encounters that does not make life any easier for either party and more so for those with less power in the situation.

Bearing these constraints in mind, we might reach a more realistic appreciation of the struggle for recognition among migrants and refugees. The 'texts' and 'contexts' of biographical narratives - which are more precisely testimonials in face of the 'state of exception' we are living in (Agamben, 2005) - can be seen in either a positive or negative way, as an obstacle for coexistence, or as bridges of understanding and dialogue. By having the opportunity to create extra-everyday life situations of encounter and dialogue in superdiverse groups like the ones with which we have worked in our projects, one might get closer to attaining recognition beyond such asymmetries.

A radical example might be given:

Daud Al Anazy is an Iraqi who arrived in Portugal in December $2015 .^{8}$ He works in a bakery owned by a Portuguese language teacher who has co-written and published his testimonial: From Mosul to Alfeizerão in 6000 words (2016). ${ }^{9}$ The short book was published to record Daud's experience throughout his difficult journey, and to inform public opinion 'carefully, in detail, and much precision' about 'a faithful portrait of what is being done and not done in our welcoming of refugees [in Portugal]' (p. 79). The small volume has nine chapters describing his reasons for and circumstances in leaving Mosul, ${ }^{10}$ the tortures and prison inflicted by Daesh, his way to Syria, his brief stay in Turkey, the shipwreck and survival in the Aegean Sea, the refugee camp in Idomeni, the Lisbon airport, and the arrival and first days in Alfeizerão (an hour north of Lisbon). In simple and clear writing, this self-published booklet contains strong descriptions of the terrible experiences Daud suffered. Throughout the short chapters, readers can learn about his motivation to write down such experiences, his editorial choices (why he opted for a version that is not the full story, not covering his more recent days). Furthermore, it includes reflections that bring a collective dimension to his account. He calls his own narrative a testimonial, and 
punctuates his descriptions with questions and comments that highlight the radical dimension of the reported experiences: feelings of hope and despair, episodes of violence and inhumanity, states of alienation - all of them bringing significance to his new life.

Illustrating the definition given by Giorgio Agamben of testimonial and witness, this autobiographical narrative shows how Daud is a survivor, as he represents the events through his storytelling. According to Agamben (1999), the witness personifies a surviving history that he or she can tell from the particular position of the one who almost died. We can read in the young Iraqi's text a poignant account of the shipwreck he survived in the Aegean Sea, 'the longest, most difficult and simultaneously most fortunate hours of my life' (p. 47). People in the water around him were drowning. A boat float kept him bobbing on the surface waiting and waiting for rescue or death - together with two little children separated from their parents who grabbed another flotation device nearby. Eventually the coast guard arrived in time and saved them from hypothermia, hunger and exhaustion. Those were 'hours, minutes without end, along which all my life was questioned and totally emptied' (p. 49). Daud was the last one to be saved. When he found himself on land, he saw everyone who had escaped that nightmare 'crying, laughing, as if not believing that they were there, alive, and saved' (p. 51). He describes his feelings in Portuguese: 'There was nothing left. There was nothing left [...] only life had stayed. Life to conquer again, from scratch, from nothing' (p. 52).

The transposition of a radical experience into a narrative is like a rebirth, a symbolic departure from the previous threatening situation that in many cases causes trauma and the psychological impossibility to speak. It is important to stress here that such a narrative brings to the surface an apparent impossibility of a shared truth with the host (incommensurability of experiences). But as much as the weaving of a narrative renews the life of the survivor after trauma, it also enables the listener to learn how to acknowledge that other truth. This is a crucial aspect that gives materiality to radical recognition since the request for a self-narrative from a refugee creates the possibility to build bridges between two opposite worlds: that of the newcomer, the asylum seeker, and that of the host, the one who sees the strangers coming with a sense of unease. Also, producing or not producing a self-narrative that gives visibility to a personal, radical experience of survival, is not the same for its author and the community of listeners or readers. The work of creation after destruction has personal and collective impacts that might make a difference in the way host countries welcome newcomers.

In his Guestbook Project, ${ }^{11}$ Richard Kearney describes the transition 'from hostility to hospitality' as being possible through the exchange of stories from different people. Exchanging stories, changing history is the key idea of his theory. Kearney has been developing a theory and practice of carnal hermeneutics that fosters dialogues between individuals and groups in conflict. Carnal hermeneutics provides a philosophical approach to the body as interpretation. Transcending the traditional dualism of rational understanding and embodied sensibility, this work argues that our most carnal sensations are already interpretations. Because interpretation truly goes 'all the way down' carnal hermeneutics rejects the opposition of language to sensibility, word to flesh, text to body (Kearney \& Treanor, 2015). More recently, Kearney is arguing for a pedagogy of narrative exchange as a means to raise hospitality and inclusion emphasising the carnal dimension of recognition (Marcelo, 2017). 
Foucault (1984) and Ricoeur (1988) had already shown how individual memory might accomplish the function of raising awareness: each voice is singular, but it manages to awaken general consciousness regarding human mortality and survival. An ethical relationship towards reality is developed through such an awareness; the knowledge that can be transmitted to others is a testimonial to the capacity to awaken them. In this sense, self-narration manages to bring to the fore a shared humanity, and biographical research creates a present of new possibilities both for the one who narrates and for the ones who are willing to listen.

Narratives of migrants and refugees bring this level of co-responsibility to the narrator and to the listeners. In the present moment of historical shift and social transformation brought about by the so-called 'migration crisis' (that is more so a crisis of our world system), the production of a narrative by a newcomer about his or her life in a host country corresponds to an 'identity in the making'. What is said, how it is said and to whom, might actually change the concrete life situation of the persons involved. And the process of biographisation happening in such narration builds the foundations for another recognition: that of the truth of someone's story (this one is mediated by the narrative function analysed by Paul Ricoeur). Self-narration, alterity in dialogue, active listening, empower narrators to become authors (in the sense of the 'one who creates'). And such creations in the form of texts and new contexts of dialogue contribute to a new social landscape embracing a culture of peace and mutual recognition. That is precisely the opposite of intolerance, impermeability and fear. In order to facilitate the reciprocities and mutuality of competences of all the participants in such research situations, the working concept is to 'get closer', regardless of religious and cultural differences that might create distances from the start. In this sense, autobiographical texts and biographical narratives of refugees empower or liberate their narrators and audiences, by simultaneously fostering awareness (and performativity) in relation to the collective dimension of individual experiences. Refugees might not yet be citizens like their hosts, but they are representatives of a common humanity that needs to be acknowledged and incorporated in our new socio-political landscapes and relations.

\section{Life storytelling and migrant's participation: pedagogy of narrative exchange}

Biographical research is optimal for understanding and analysing the concrete ways in which abstract ideas about identity and the Other are conceived, learned and practised by concrete interlocutors. It recognises its interlocutors as subjects of dialogue before and beyond the limits of the research context of communication and encounter. The other, as a subject of interaction in our research settings, is validated, valorised and acknowledged in his/her singularity as a person and agent of knowledge. Furthermore, a transition 'from hostility to hospitality' is made possible through the exchange of stories (Kearney, 2009) as the humanity of strangers and hosts get to be known and acknowledged concretely. The anthropological concept of experience (Turner \& Bruner, 1986) lies at the heart of this assumption, as the experience of our interlocutors is what nourishes the study of migrations from a biographical perspective. Furthermore, what happens in the research situation when we gather and share personal stories is also an experience per se for all parties involved: awareness raising, learning processes and 
peace-building. Together, the participants in an exchange of self-narrated stories might actually learn how to carefully listen to the different other, might break barriers, cycles of symbolic and material violence or intolerance, and co-construct a new collective narrative. So, it is not merely 'the human actor back on stage' (Renders, de Haan, \& Harmsma, 2017) that is at stake in biographical research, it is also - and this is deeply significant-, the social actor as a subject of history that becomes concretely known, acknowledged and participating in social transformation. A historical agent of local transformations.

In a very important and effective way biographical research integrates in its theories and methods the capacity to dignify, as it is one of the few kinds of social research that does not objectify its interlocutors. It also promotes a discussion on the ethics of narration from a hermeneutical point of view (Meretoja, 2014; Meretoja \& Davis, 2017). Biographical Research accepts the subjectivity and inter-subjectivity of human relations in the very process of research (Ferrarotti, 1981; Lechner, 2011). This does not mean that power relationships, subject positions or social statuses are overlooked, as already shown. Especially when considering that working with refugees and migrants is an intercultural venture that will necessarily result in mutual learning and social transformation at micro levels, also in the historical corrective sense (Hamilton, 2017) since official discourses about history are not necessarily true.

In a historical moment of growing extremisms, and in the face of fundamental contradictions between established political values and concrete actions and discourses in our own societies (democracies violating human rights, for example, or governments going against established principles and laws), it is clear that the work with narratives and life stories brings attention and importance to the 'wretched of the Earth' (Fanon, 1961) thus assuming a utopian position.

The present analysis proposes a constructive bio-political contribution of biographical work with migrants and refugees claiming for a concrete utopianism of social justice (Wright, 2010) achieved through a pedagogy of narrative exchange. It takes the form of a substantial transformation of the present configuration of social relations, for which we do not expect immediate accomplishment. Nonetheless, these goals are not impossible to realise, especially so at local or group levels. Political will, media discourses, local and global actions might reach some steps of this utopian project. A participatory kind of research, just like the action-research proposed by Kurt Lewin right after the Second World War (1946), helps us to develop concrete projects with effects in local communities. Our experience indicates that this is not only reasonable, but necessary if we do not want to be compliant with more destructive solutions in face of the presumed difficulty of living together and accepting differences. That is what we promote in our biographical research projects, and the results are effective in what concerns the formative, transformative effects for participants and researchers. Also, along the research process, there is real participation happening for the volunteers. Such experiences have been described by our interlocutors as particularly meaningful and have the potential to lead to concrete actions and policies for social cohesion, if there were political will.

\section{Concluding remarks}

In this paper, I advocate for a theoretical-practical coherence between the means and ends of biographical research. Drawing from empirical work developed with migrants and refugees in Portugal from many different origins and social profiles, I take the stance of 
public social research based on the theoretical contribution of qualitative sociology, anthropological work on transnational migrations and biographies, and the 'carnal hermeneutics' of Irish philosopher Richard Kerney. To acknowledge the practical effects of biographical research in social transformation and participation, the text refers to the important contribution of the current of life histories in education, initiated in the 1980s by Gaston Pineau. This has been - ever since - a very active biographical research, dedicated to the practice of life storytelling in educational settings, broadly understood as formal, informal and non-formal education (or life-long training), simultaneously.

At the centre of such theoretical-practical coherence, this paper identifies the question of recognition both as an abstract presupposition and a concrete consequence of (meaningful) biographical research. The sharing of narratives, the dialogue that puts in constructive confrontation different world views and experiences, different personal truths, builds concrete forms of recognition that enable migrants and refugees to participate in society in less unequal frames. It also enables new forms of social relations between different subject positions (researchers and participants), claiming for a humanistic understanding of the research endeavour in itself. Such claims are not new, and can be found in referential works of 'classical' biographical research in American and European traditions.

The present historical moment characterised by massive migrant (forced and volunteered) movements and displacements (by the so-called migration crisis exacerbated by military conflicts and environmental disasters) has put in evidence the internal contradictions of western democracies when dealing with super-diversity and multiculturalism. Also, the management of massive migrations is not indifferent to big financial and economic interests that fuel military conflicts and political un-solutions. Therefore, migrants and refugees are the immediate scapegoats of populistic perspectives and discourses, where they actually represent the mirror of western civilisational inconsistences and discontents. In such scenarios, biographical research might well choose to either reify obsolete representations and forms of knowledge production or, to the contrary, contribute to historical transformation. At a microlevel, my team and I believe that biographical research helps to form, inform and transform the situational injustices identified in the research processes with migrants and refugees. For the sake of simple coherence, then, we stand for a public 'migrants' live matter' research position.

\section{Notes}

1. Portugal has been one of the best evaluated countries in Europe by the MIPEX Prizes in the last years, after Sweden. Such evaluation considers mainly the laws concerning immigrants and immigration policies in each country but is not indifferent to a general common sense and media discourses transmitting a mythical idea of Portugal as being a very tolerant, nonviolent and non-racist country. If comparatively to other countries in the EU this might be true, the fact is that most migrants have different portraits to draw and testify against such myths.

2. A recent report by the European Committee for the Prevention of Torture and Inhuman Treatment urges Portuguese authorities to tackle police violence, namely concerning persons of African descent, both Portuguese citizens and foreign nationals, appearing to be at greater risk of being ill-treated (www.coe.int/en/web/cpt/home). Similarly, a recent study about institutional racism in Portuguese schools has shown that immigrant students and descents are victims of racism and affected by institutional racism in their educational trajectories (Seabra, Mateus, Matias, \& Roldão, 2018). 
3. Project 'Biographical research and the study of migrations: building a collaborative framework in the Portuguese context', funded by the Portuguese National Science Foundation (FCT), ref.: PTDC/CS-ANT/111721/2009-FCOMP-01-0124-FEDER-014442.

4. The project in the context of the International Conference Cities is presented in Coimbra, June 2012, seminar 'Urban ruminations: tell your city at a stories circle'.

5. The level of fluency in Portuguese varied from case to case. We have organised the groups according to specific categories (students, workers, women, etc.) to minor language competences but still there were performance differences.

6. Biographical workshop animated by Prof. Jeanne-Marie Rugira, University of Paris, 8 June 2004.

7. A final videotaped interview we have made individually with the project' participants shows how important this was for them and how much they all are willing to repeat the experience.

8. This story and passage also appear in a text the author has written for the Special Issue of $a / b$ : Auto/Biography Studies, 'Excavating Lives', issue 32.3, Rutgers, 2017. Daud Al Anazy's book was published and publicised online in 2016 but we had the chance to meet each other in person in October 2017. It was during a national pastries exhibition for 'Conventual Sweets' in Coimbra that a direct conversation happened around the reported radical experience he endured. Daud (pseudonym that he chose for the book) works in a pastry shop owned by his Portuguese language teacher who produces the typical 'Sweet Bread of Alfeizerão', her hometown. This work about Daud was part of the author's other Project 'Participatory Media Biographical Research with Migrants to and from Portugal', funded by the Portuguese National Science Foundation (FCT), ref.: IF/00107/2013.

9. De Mosul a Alfeizerão em 6000 palavras (self-published book). All quotes translated from Portuguese by the author.

10. Like in many other cases of young refugees and migrants from endangered zones of the globe, Daud left home after his family decision. His father sent him to the uncertain journey of escape after the death of two older sons killed in Iraq by the Daesh. For an analysis of patterns of action and interpretation within the dynamics of war and migration in relation to family decision see, for example, Arne Worm (2017).

11. The Guestbook Project is a digital platform promoting the power of digital storytelling as a means of healing divisions. Considering that 'change happens when pain is turned into poetry in the crossing of narratives', this work directed by Irish Philosopher Richard Kearney gives young people the opportunity to create peace by exchanging stories and turning them into creative digital projects that can inspire change all over the world. The goal is to experiment through life storytelling how hospitality can take place among people from conflicting communities. See www.guestbookproject.org.

\section{Disclosure statement}

No potential conflict of interest was reported by the author.

\section{Funding}

This work was supported by the Fundação para a Ciência e a Tecnologia (Portuguese National Science Foundation) under the research projects PTDC/CS-ANT/111721/2009-FCOMP-01-0124FEDER-014442 and IF/00107/2013.

\section{Notes on contributor}

Elsa Lechner, PhD in Social Anthropology by the Ecole des Hautes Etudes en Sciences Sociales (Paris, 2003) is a senior researcher at the Center for Social Studies-University of Coimbra since 2009. Fulbright Visiting Scholar at Brown and Rutgers-Newark Universities (2014/15), PostDoc at the Institute for Social Sciences and ISCTE (Lisbon, 2003-2009), she is presently coordinating an international 
research project co-funded by the Gulbenkian Foundation, dedicated to life stories, memories and new narratives on Portuguese emigration to Brazil, France, and the USA.

\section{References}

Agamben, G. (1999). The remnants of Auschwitz: The witness and the archive. New York, NY: Zone Books.

Agamben, G. (2005). State of exception (Kevin Attell, Trans. and Ed.). Chicago, IL: University of Chicago Press.

Agier, M. (2010). Managing the undesirables. Cambridge: Polity Press.

Al Anazy, D., \& Franco, H. L. (2016). De Mosul a Alfeizerão. Portugal: Self-Published Book.

Devereux, G. (1967). From anxiety to method in the behavioral sciences. The Hague: Mouton.

Fanon, F. (1961). Les Damnés de la Terre. Paris: Maspero.

Ferrarotti, F. (1981). On the autonomy of the biographical method. In D. Bertaux (Ed.), Biography and society: The life history approach in the social sciences (pp. 19-27). London: Sage.

Ferrarotti, F. (2014). História e histórias de vida. O método biográfico nas Ciências Sociais. Natal: EDURFN.

Foucault, M. (1984). Histoire de la sexualité, Tome 3, Le souci de soi, Gallimard.

Geertz, C. (1973). The interpretation of cultures. New York, NY: Basic Books.

Giordano, C. (2008). Practices of translation and the making of migrant subjectivities in contemporary Italy. American Ethnologist, 35(4), 588-606.

Glick-Schiller, N., \& Fouron, G. (2001). George woke up laughing: Long-distance nationalism and the search for home. Durham: Duke University Press.

Guth, S. (2004). Chicago 1920. Aux origines de la sociologie qualitative. Paris: Téraèdre.

Hamilton, N. (2017). Biography as corrective. In H. Renders, B. Haan, \& J. Harmsma (Eds.), The biographical turn: Lives in history (pp. 15-30). London: Routledge.

Honneth, A. (1996). The struggle for recognition, the moral grammar of social conflicts. Cambridge, MA: Polity Press.

Honneth, A. (2014). Freedom's right. The social foundations of democratic life. New York, NY: Columbia University Press.

Kearney, R. (2009). Guestbook Project - turning hostility to hospitality. Boston, MA. Retrieved from www.guestbookproject.org

Kearney, R., \& Treanor, B. (2015). Carnal hermeneutics. Perspectives in continental philosophy. New York, NY: Fordham University Press.

Lechner, E. (2011). La recherche biographique aujourd'hui: De science de l'incertitude à savoir ancrée. Le Sujet Dans la Cité, Habiter en étranger: Lieux, Mouvements, Frontières (2, pp. 214-226). Paris: Téraèdre.

Lechner, E. (2012). Biographical workshops: Research, pedagogy, and ecology of knowledges. Revista Educação e Realidade, 37(1), 71-85.

Leray, C., \& Hamey Warou, F. (2014). L'Arbre à Palabres et Récits. Paris: L'Harmattan.

Lewin, K. (1946). Action research and minority problems. Journal of Social Issues, 2, 34-46.

Marcelo, G. (2017). Narrative and recognition in the flesh. An interview with Richard Kearney. Philosophy \& Social Criticism Journal, 43(8), 777-792.

Mbembe, A. (2003). Necropolitics. Public Culture, 15(1), 11-40.

McGranahan, C. (2010). Narrative dispossession: Tibet and the gendered logics of historical possibility. Comparative Studies in Society and History, 52(4), 768-797.

Meretoja, H. (2014). The narrative turn in fiction and theory: The crisis and return of storytelling from Robbe-Grillet to Tournier (pp. xviii, 282). Palgrave Studies in Modern European Literature. New York, NY: Palgrave Macmillan.

Meretoja, H., \& Davis, C. (2017). Storytelling and ethics. Literature, visual arts and the power of narrative. London: Routledge.

O'Neill, B. (2009). Histórias de vida em antropologia: estilos e visões, do etnográfico ao hipermoderno. In E. Lechner (Ed.), Histórias de Vida: Olhares Interdisciplinares (pp. 109-121). Porto: Afrontamento. 
O'Neill, M., Roberts, B., \& Sparkes, A. C. (Eds.). 2015. Advances in biographical methods. Creative applications. Abingdon: Routledge.

Pineau, G. (1996). Les Histoire de vie comme art formateur de l'existence. Pratiques de Formation/ Analyses, 31, 65-80.

Renders, H., de Haan, B., \& Harmsma, J. (2017). The biographical turn: Lives in history. London: Routledge.

Ricoeur, P. (1988). L'Identité Narrative. Revue Esprit, pp. 295-306.

Roberts, B. (2007). Getting the most out of the research experience. What every researcher needs to know. London: Sage.

Rodier, C. (2013). Xénophobie business. À quoi servent les contrôles migratoires? Paris: La Découverte.

Rosenthal, G., \& Bogner, A. (2017). Biographies in the global south. Life stories embedded in figurations and discourses. Frankfurt: Campus Verlag.

Ruokonen-Engler, M.-K., \& Siouti, I. (2013). 'Doing biographical reflexivity' as s methodological tool in transnational research setting. Transnational Social Review, 3(2), 247-261.

Santos, B. S. (2007). Beyond abyssal thinking: From global lines to ecologies of knowledges. Review, $X X X-1,45-89$.

Seabra, T., Mateus, S., Matias, A. R., \& Roldão, C. (2018). Imigração e escolaridade: trajetos e condições de integração. In R. M. Carmo, J. Sebastião, J. Azevedo, S. Martins, \& A. Firmino da Costa (organizadores), Desigualdades Sociais. Portugal e a Europa (pp. 301-314). Lisboa: Editora Mundos Sociais, ISCTE.

Thomas, W. I. (1912). Race psychology: Standpoint and questionnaire, with particular reference to the immigrant and the Negro. The American Journal of Sociology, XVII, 725-775.

Thomas, W. I. (1914). The Prussian-Polish situation: An experiment in assimilation. The American Journal of Sociology, XIX, 624-639.

Turner, V., \& Bruner, E. (1986). The anthropology of experience. Champaign-Urbana, IL: University of Illinois Press.

Vertovec, S. (2007). Super-diversity and its implications. Journal of Ethnic and Racial Studies, 30(6), 1024-1054.

Williams, R. (1997). Hegel's ethics of recognition (450 pp.). Berkeley: University of California Press.

Worm, A. (2017). Civil war and the figurations of illegalized migration. Biographies of Syrian migrants coming to the European Union. In G. Rosenthal \& A. Bogner (Eds), Biographies in the global south. Life stories embedded in figurations and discourses (pp. 160-184). Frankfurt: Campus Verlag.

Wright, E. O. (2010). Envisioning real utopias. London: Verso. 